\title{
O Poder Psicoativo dos Alimentos: Análise de um Caso de Intoxicação com Noz-Moscada
}

\author{
The Psychoactive Power of Foods: A Case of Acute \\ Nutmeg Intoxication
}

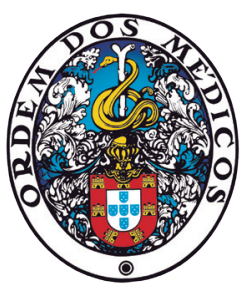

\author{
Desidério DUARTE ${ }^{1}$, Marta MENDONÇA ${ }^{2}$, Luís RAMOS ${ }^{1}$ \\ Acta Med Port 2021 Apr;34(4):298-300 - https://doi.org/10.20344/amp.12541
}

\section{RESUMO}

A ingestão de noz-moscada em doses elevadas provoca consequências médicas e psiquiátricas potencialmente graves e incapacitantes. Nenhum componente isolado da noz-moscada foi identificado como responsável por todos os sintomas observados durante a intoxicação, contudo, acredita-se que a miristicina, que é um dos componentes dos óleos essenciais desta especiaria, é o responsável pela maioria dos efeitos psicoativos, embora o mecanismo exato não seja conhecido. Outros constituintes, como a elemicina, também podem estar envolvidos. Os sintomas da intoxicação iniciam-se três a seis horas após a sua ingestão, remitindo nas primeiras 24 a 48 horas, e normalmente não deixam sequelas. Neste trabalho apresentamos o caso de um homem que após o consumo de 18 a 28 g de noz-moscada desenvolveu um episódio psicótico grave, com discurso desorganizado, agitação psicomotora e ideação delirante mística/grandiosa. A sintomatologia remitiu rapidamente e após um ano de estabilidade clínica sem terapêutica, teve alta da consulta da especialidade.

Palavras-chave: Condimentos/intoxicação; Intoxicação; Myristica/intoxicação; Perturbações Psicóticas/etiologia

\section{ABSTRACT}

Ingestion of high doses of nutmeg causes potentially serious and disabling medical and psychiatric consequences. No isolated component of nutmeg has been identified as responsible for all symptoms observed during intoxication, however myristicin, one of the essential oil's components of this spice, is believed to be responsible for most psychoactive effects, although the exact mechanism is not known. Other constituents, such as elemicin, may also be involved. Symptoms of intoxication begin three to six hours after ingestion, resolve within the first 48 hours, and usually leave no sequelae. In this paper we present the case of a patient who after consuming 18 to $28 \mathrm{~g}$ of nutmeg developed a severe psychotic episode, with disorganized speech, psychomotor agitation and mystical/grandiose delusional ideation. The symptoms resolved quickly, and after one year of clinical stability without therapy, was discharged from the specialist consultation.

Keywords: Condiments/poisoning; Myristica/poisoning; Poisoning; Psychotic Disorders/etiology

\section{INTRODUÇÃO}

A noz-moscada foi introduzida na Europa por comerciantes árabes durante o século XII, tendo sido apenas no século XVI que os Portugueses descobriram na Indonésia a árvore de onde provém, a moscadeira: myristica fragrans. ${ }^{1}$

Ao longo de séculos esta substância tem sido utilizada não só na culinária devido às suas propriedades aromáticas, mas também na medicina, no tratamento da patologia reumática, cólera, cólicas gástricas, náuseas, flatulência, diarreia e para reduzir o fluxo menstrual. ${ }^{2}$

As suas propriedades psicoativas foram descritas pela primeira vez na Idade média por Hildegard von Bingen, tendo sido utilizado como alucinogénio e agente euforizante durante as cruzadas. ${ }^{2} \mathrm{O}$ primeiro caso conhecido de intoxicação ocorreu em 1576 na Inglaterra, quando uma grávida ingeriu mais de 10 destas nozes. ${ }^{3}$

Entre 1960 e 1970 a cultura hippie divulgou esta substância como uma alternativa barata a outras drogas psicadélicas, tendo sido rapidamente abandonada devido à cefaleia intensa que se segue à sua ingestão em doses elevadas. ${ }^{4,5} \mathrm{Um}$ estudo desenvolvido na Califórnia constatou que atualmente, os abusadores desta substância são em pequeno número e maioritariamente jovens do sexo masculino que consomem várias drogas..$^{3,6}$

A autointoxicação acidental como a relatada neste trabalho é rara, uma vez que são necessárias doses consideráveis para produzir efeitos alucinogénios, representando menos de $20 \%$ dos casos de intoxicação publicados. ${ }^{4}$

\section{CASO CLÍNICO}

Doente do sexo masculino, 29 anos, leucodérmico, sem acompanhamento prévio em psiquiatria e sem antecedentes médicos relevantes. Foi trazido ao serviço de urgência pela família por alterações de comportamento com 24 horas de evolução. No dia anterior, após o almoço, tinha iniciado quadro de risos imotivados, discurso desorganizado e agitação psicomotora (exemplo: fazia corridas sem objetivo aparente). Na admissão apresentava discurso ilógico e pensamento desorganizado com ideação delirante mística/grandiosa, referindo possuir poderes sobrenaturais. Encontrava-se normotenso, com discreta taquicardia sinusal (107 bpm). Os exames efetuados (tomografia computorizada crânio-encefálica - TC-CE, eletrocardiograma e análises ao sangue e urina com doseamentos de substâncias psicotrópicas) não revelaram alterações. Ficou internado

1. Departamento de Psiquiatria e Saúde Mental. Centro Hospitalar Universitário do Algarve. Faro. Portugal.

2. Medicina Geral e Familiar. Unidade de Saúde Familiar Ria Formosa. Faro. Portugal.

$\triangle$ Autor correspondente: Desidério Duarte. desiderio.duarte@gmail.com

Recebido: 09 de julho de 2019 - Aceite: 30 de setembro de 2019 - First published: 06 de janeiro de 2020 - Online issue published: 01 de abril de 2021 Copyright $\odot$ Ordem dos Médicos 2021 
voluntariamente no serviço de psiquiatria (para esclarecimento do quadro clínico) com o diagnóstico de psicose não especificada, tendo iniciado terapêutica com olanzapina 10 mg e lorazepam $1 \mathrm{mg}$.

No dia seguinte apresentava remissão da atividade delirante, apresentando apenas uma ligeira elação de humor. Nessa altura informou que no pequeno-almoço que antecedeu o início do quadro clínico tinha ingerido noz-moscada, aspeto que até essa altura não tinha referido por não valorizar. Informou que o consumo dessa especiaria era frequente, contudo nesse dia foi em maior quantidade - ingeriu três a quatro nozes (18 a $28 \mathrm{~g}){ }^{1}$

Colocou-se então como hipótese mais provável a intoxicação acidental por noz-moscada (myristica fragrans). Durante o internamento manteve a estabilidade hemodinâmica, não voltando a apresentar alterações do comportamento, pensamento ou do discurso. Teve alta 10 dias após a sua admissão, medicado com olanzapina $5 \mathrm{mg} / \mathrm{dia}$.

Na consulta efetuada dois meses após a alta, mantinha-se assintomático tendo já interrompido a medicação. Após um ano mantinha a estabilidade clínica sem terapêutica, tendo tido alta da consulta da especialidade.

\section{DISCUSSÃO}

A noz-moscada é constituída por matéria sólida $(5 \%$ a $60 \%$ ) e óleos (30\% a $55 \%$ ) que são de dois tipos: óleo essencial (5\% a $15 \%)$ e óleo fixo (24\% a $40 \%) .{ }^{7}$ É o óleo essencial que contém miristicina, substância que se afigura como responsável pela maioria dos efeitos psicoativos, embora o mecanismo exato não seja conhecido. Estudos laboratoriais com animais sugerem que a miristicina pode ser metabolizada em 3-metoxi-4, 5-metilenodioxi-anfetamina (MMDA), um composto psicoativo conhecido, contudo não é claro que isso ocorra da mesma forma em humanos. ${ }^{3,4}$

A miristicina está igualmente implicada na inibição da monoamina oxidase tendo a sua atividade antidepressiva sido comprovada em diversos estudos com roedores. ${ }^{8,9}$

A concentração na noz-moscada de miristicina é de $1 \%$ a $3 \%$, pelo que outros compostos podem estar igualmente relacionados com o quadro clínico provocado pelo consumo exagerado desta especiaria. A elemicina é um desses elementos, tendo demonstrado efeitos negativos na coordenação de roedores. ${ }^{3}$

Uma colher de sopa de noz-moscada contém aproximadamente 6 a $7 \mathrm{~g}$, sendo utilizada para fins recreativos em doses entre 5 e $30 \mathrm{~g}$, em função da quantidade de óleos essenciais do fruto. ${ }^{1}$ Os sintomas da intoxicação com noz-moscada iniciam-se três a seis horas após a sua ingestão, remitem nas primeiras 24 a 48 horas e não deixam sequelas. ${ }^{1,6}$ Os seus efeitos são dose dependentes: os sintomas neuropsicológicos geralmente só se desenvolvem após o consumo de $10 \mathrm{~g}$, surgindo a obnubilação após $18 \mathrm{~g}$, e os

\section{REFERÊNCIAS}

1. Barceloux DG. Nutmeg (Myristica fragrans Houtt). Dis Mon. 2009;55:3739.

2. Beyer J, Ehlers D, Maurer $\mathrm{HH}$. Abuse of nutmeg (Myristica fragrans efeitos anticolinérgicos após 25 a $28 \mathrm{~g} .{ }^{1}$ Ocorre com maior frequência taquicardia, agitação e inquietação sendo que apenas alguns doentes desenvolvem delírios, episódios dissociativos e alucinações visuais, auditivas ou tácteis. ${ }^{3,5,10}$

A literatura não é consensual quanto à ocorrência de mortes provocadas por esta substância. Alguns estudos referem não existir relação direta entre a intoxicação e o óbito, enquanto outros referem a ocorrência de dois casos. ${ }^{1,3}$

O diagnóstico de intoxicação por noz-moscada é clínico, não existindo até ao momento biomarcadores. ${ }^{2}$ De salientar que as análises de rotina ao sangue e a pesquisa de metabolitos na urina, geralmente permanecem sem alterações e que o tratamento é de suporte. ${ }^{1}$

Neste caso o doente ingeriu entre 18 e $28 \mathrm{~g}$ de noz-moscada, mas não apresentou obnubilação, destacando-se principalmente a agitação e a sintomatologia psicótica, o que aliado à raridade da situação, dificultou o diagnóstico inicial e motivou a introdução de olanzapina. Desta forma, o diagnóstico só foi confirmado definitivamente com o acompanhamento da evolução do doente.

De salientar que inúmeros outros alimentos podem-se tornar tóxicos se ingeridos em quantidades elevadas. Destaca-se a título de exemplo a baunilha, que possui heliotropina, uma substância com efeito antidepressivo, e a pimenta preta, que como contém piperina, aumenta a serotonina e as endorfinas. ${ }^{11}$ Os doentes nem sempre fornecem informações voluntárias sobre a sua ingestão, podendo inclusivamente não estar despertos para os seus efeitos adversos. É essencial que os clínicos estejam atentos e perguntem especificamente sobre o consumo destes e doutros alimentos, especialmente aqueles que estão descritos como potencialmente causadores de sintomatologia médica/psiquiátrica.

\section{CONSENTIMENTO INFORMADO E APROVAÇÃO ÉTICA}

Os autores declaram que o estudo foi aprovado pela Comissão de Ética para a Saúde do Centro Hospitalar Universitário do Algarve. A confidencialidade e a privacidade dos dados foram garantidas de acordo com a Declaração de Helsínquia.

\section{CONSENTIMENTO INFORMADO}

Obtido.

\section{CONFLITOS DE INTERESSE}

Os autores declaram que não existem conflitos de interesse para a realização deste trabalho.

\section{FONTES DE FINANCIAMENTO}

Para a realização deste trabalho os autores declaram que não receberam financiamento específico de nenhuma entidade pública ou privada. 
75.

3. Carstairs SD, Cantrell FL. The spice of life: an analysis of nutmeg exposures in California. Clin Toxicol. 2011;49:177-80.

4. Roeters van Lennep JE, Schuit SC, Van Bruchem-Visser RL, Özcan B. Unintentional nutmeg autointoxication. Neth J Med. 2015;73:46-8.

5. Williams EY, West $F$. The use of nutmeg as a psychotropic drug: report of two cases. J Nat Med Assoc. 1968;60:289-90.

6. Ehrenpreis JE, DesLauriers C, Lank P, Armstrong PK, Leikin JB. Nutmeg poisonings: a retrospective review of 10 years' experience from the Illinois Poison Center, 2001-2011. J Med Toxicol. 2014;10:148-51.

7. Oliveira GF. Noz-moscada, myristica fragans, houtt: um estudo de composição e efeito do consumo crónico no comportamento de animais de laboratório. Rio Grande, 2007. [consultado 2018 out 6]. Disponível em: http://repositorio.furg.br/bitstream/handle/1/ 3551/noz-
moscada+myristica+fragans+houtt.pdf;jsessionid=641716C84AF2709F 80F20E11 4BE9D33F?sequence=1.

8. Dhingra $D$, Sharma A. Antidepressant-like activity of $n$-hexane extract of nutmeg (myristica fragrans) seeds in mice. J Med Food. 2006;9:84-9.

9. Moinuddin G, Devi K, Kumar Khajuria D. Evaluation of the antidepressant activity of myristica fragrans (nutmeg) in male rats. Avicenna J Phytomed. 2012;2:72-8.

10. Fleurentin $\mathrm{C}$. Thérapeutique par les psychotropes psychédéliques: these. Metz 1988. [consultado 2018 out 6]. Disponível em: http://docnum. univ-lorraine.fr/public/BUPHA_T_2015_FLEURENTIN_CHARLES.pdf.

11. Bourgeois J, Parthasarathi $\bar{U}$, Hategan A. Taking the spice route: psychoactive properties of culinary spices. Curr Psychiatr. 2014;13:2132. 